\title{
How Well Can Medicare Records Identify Seniors with Cognitive Impairment Needing Assistance with Financial Management?
}

David Weir and Kenneth Langa

Project \#: R-UM18-03 


\title{
How Well Can Medicare Records Identify Seniors with Cognitive Impairment Needing Assistance with Financial Management?
}

\author{
David Weir \\ University of Michigan \\ Kenneth Langa \\ University of Michigan
}

October 2018

\author{
Michigan Retirement Research Center \\ University of Michigan \\ P.O. Box 1248 \\ Ann Arbor, MI 48104 \\ www.mrrc.isr.umich.edu
}

(734) 615-0422

\section{Acknowledgements}

The research reported herein was performed pursuant to a grant from the U.S. Social Security Administration (SSA) funded as part of the Retirement Research Consortium through the University of Michigan Retirement Research Center Award RRC08098401-10. The opinions and conclusions expressed are solely those of the author(s) and do not represent the opinions or policy of SSA or any agency of the federal government. Neither the United States government nor any agency thereof, nor any of their employees, makes any warranty, express or implied, or assumes any legal liability or responsibility for the accuracy, completeness, or usefulness of the contents of this report. Reference herein to any specific commercial product, process or service by trade name, trademark, manufacturer, or otherwise does not necessarily constitute or imply endorsement, recommendation or favoring by the United States government or any agency thereof.

\section{Regents of the University of Michigan}

Michael J. Behm, Grand Blanc; Mark J. Bernstein, Ann Arbor; Shauna Ryder Diggs, Grosse Pointe; Denise Ilitch, Bingham Farms; Andrea Fischer Newman, Ann Arbor; Andrew C. Richner, Grosse Pointe Park; Ron Weiser, Ann Arbor; Katherine E. White, Ann Arbor; Mark S. Schlissel, ex officio 


\title{
How Well Can Medicare Records Identify Seniors with Cognitive Impairment Needing Assistance with Financial Management?
}

\begin{abstract}
Aging countries should have an interest in policies to assist older beneficiaries in managing finances when there is a need. This project investigated the value of Medicare records as a guide to identifying persons with cognitive impairment in need of assistance with financial management. It used data from the Health and Retirement Study (HRS) on persons 65 and older, who consented to linkage to Medicare records at a rate of approximately 90 percent. Sampling weights were adjusted to account for linkage rates. The HRS survey data provided direct evidence on cognitive impairment and difficulty managing finances. The Medicare records are an imperfect guide to cognitive impairment as a medical diagnosis. About 40 percent of persons with impairment consistent with dementia are not identified in Medicare, and about 40 percent of persons with a diagnosis in Medicare records do not have impairment that severe. The records are even worse as a guide to who perceives or is perceived by others as needing assistance with financial management. Outside of institutional settings, Medicare records identify fewer than half the people needing assistance with financial management, and point to a substantial number of people who say they do not. The use of Medicare records alone to identify older beneficiaries in need of assistance with financial management would lead to substantial errors in coverage.
\end{abstract}

\section{Citation}

Weir, David and Kenneth Langa. 2018. "How Well Can Medicare Records Identify Seniors with Cognitive Impairment Needing Assistance with Financial Management?" University of Michigan Retirement Research Center (MRRC) Working Paper, WP 2018-391. Ann Arbor, MI. https://mrdrc.isr.umich.edu/publications/papers/pdf/wp391.pdf

\section{Authors' acknowledgements}

We acknowledge support for the Health and Retirement Study (HRS) from the National Institute on Aging (NIA U01AG009740), with additional support from SSA. 


\section{Introduction}

Alzheimer's Disease and Alzheimer's Disease Related Dementias are the most burdensome of the chronic diseases of aging. The cognitive impairments that accompany these conditions lead to limitations in and eventually loss of abilities needed to live independently, creating a burden on family members for support and care, and on public resources for institutional care. One recent estimate put the cost of care in the United States at \$200 billion per year, half of which is for unpaid family care (Hurd et al. 2013). Because incidence and prevalence of dementia rise rapidly at older ages, the aging of the population will greatly increase the number of cases - a near tripling by 2050 in the US and around the world.

There is also a concern about the need for assistance with financial management among elderly persons with cognitive impairment. While transferrable wealth, such as home equity, individual retirement accounts, and defined-contribution pension accounts, are at greater risk of loss, monthly Social Security benefits account for such a large part of the income of older persons that mismanagement would directly affect well-being. Figure 1 shows the share of income from Social Security benefits by cognitive status and need for financial assistance (definitions and measures of those categories are described later in the paper). Dependence on Social Security increases as cognitive impairment increases, due mainly to their joint dependence on age. Social Security accounts for more than two-thirds of the household income of persons with severe cognitive impairment.

Addressing this concern is not a simple matter. Our purpose here is not to advocate for or against a particular policy, but to ask how a government agency could become aware of cognitive impairment in a beneficiary. In this paper we examine the potential use of Medicare records. How well can Medicare records identify persons in need of assistance with financial management? 
Figure 1: Share of social security in total household income, by cognitive status and selfreported difficulty managing money

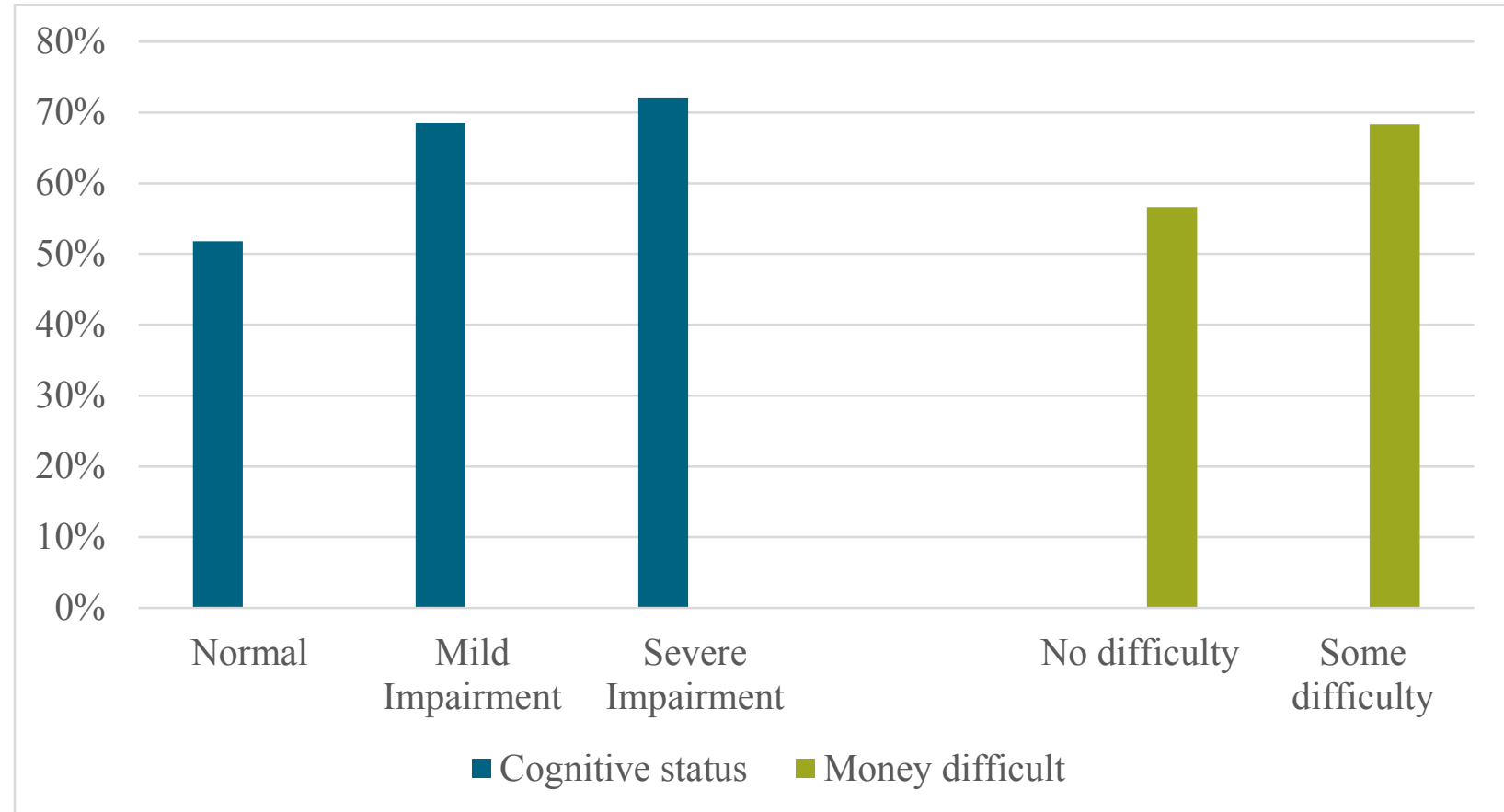

Source: HRS2014, persons 70 and older. Social Security income includes imputed amounts of Medicare premia; household income includes in addition imputed required minimum distributions from individual retirement accounts.

\section{HRS data}

We address the question using the Health and Retirement Study (HRS). The HRS has linked Medicare records on about 90 percent of its participants 70 and older. Because HRS only begins asking for consent to link to Medicare records when respondents become eligible at age 65 , the rate of coverage is substantially lower under age 70 (see Figure 2). Moreover, it takes some time in the Medicare system to accumulate provider visits sufficient to document health condition. Thus, we will primarily focus on the $70+$ population in this paper. In addition to Medicare records, HRS also has direct assessment of cognitive status, the need for assistance with financial management, and the availability of family or institutional care. 
Figure 2: Medicare linkage rates in HRS, by age

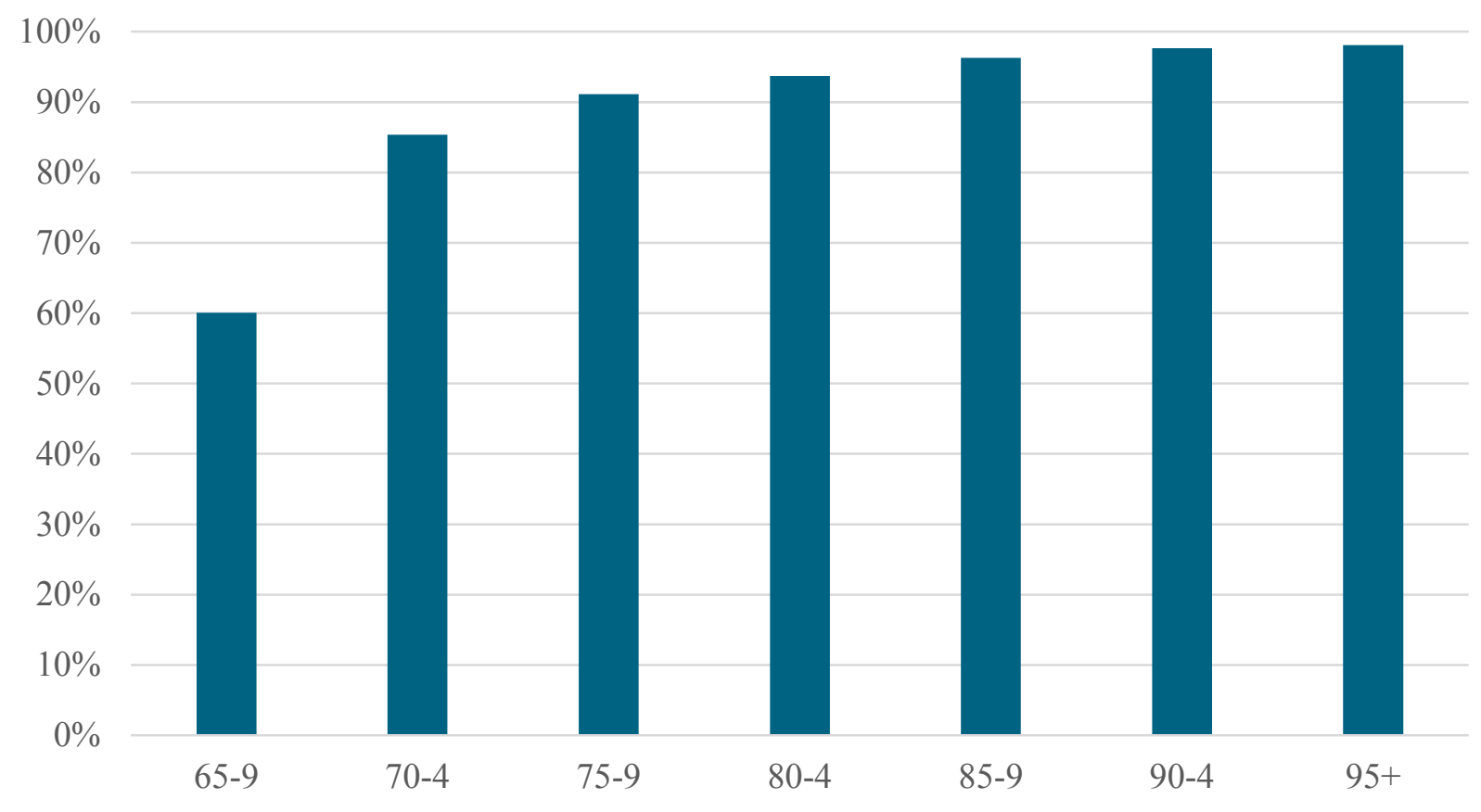

Source: HRS2016 early release, persons 65 and older, authors' sampling weights

We have assigned cognitive status using measures available in the HRS. In previous work, we developed assignments for all of HRS, including the younger than 65 participants, using measures available at all ages (Langa, Kabeto, and Weir 2009; Crimmins et al. 2011). For this research focused on the $70+$ population, we use additional measures available only for participants 65 and older. For those who complete their own interview, the measures used are immediate and delayed word recall, serial-7s, backward counting from 20, a set of eight orientation items from the Telephone Interview for Cognitive Status (TICS), and self-reported difficulties with instrumental activities of daily living. When a proxy interview is taken on behalf of a participant, we use the proxy's rating of subject memory, the interviewer's rating of whether cognition was a reason for proxy, the Jorm IQCODE, and proxy-reported difficulties with instrumental activities of daily living. Both the self and proxy scales were then related to the conventional neuropsychological diagnoses in the HRS Aging, Demographics, and Memory 
(ADAMS) substudy to determine cutpoints in the scales for mild cognitive impairment (cognitive impairment not dementia, or CIND) and severe cognitive impairment (dementia).

\section{Sources of support}

We classified living arrangements along three dimensions of potential support: spouse, children, and institutional. For each individual, we determined whether a spouse or partner was present and whether that spouse was cognitively impaired. We classified potential support from children as co-resident, living within 10 miles, living more than 10 miles away, or childless. We classified the residence as community, assisted living providing meals (thus relieving the need to shop for food), and nursing home.

Figure 3 shows that the vast majority of older persons live in private homes and apartments. Even among the most severely impaired, only about one-quarter live in institutional settings that provide for basic needs.

\section{Figure 3: Residential living arrangements, by cognitive status}

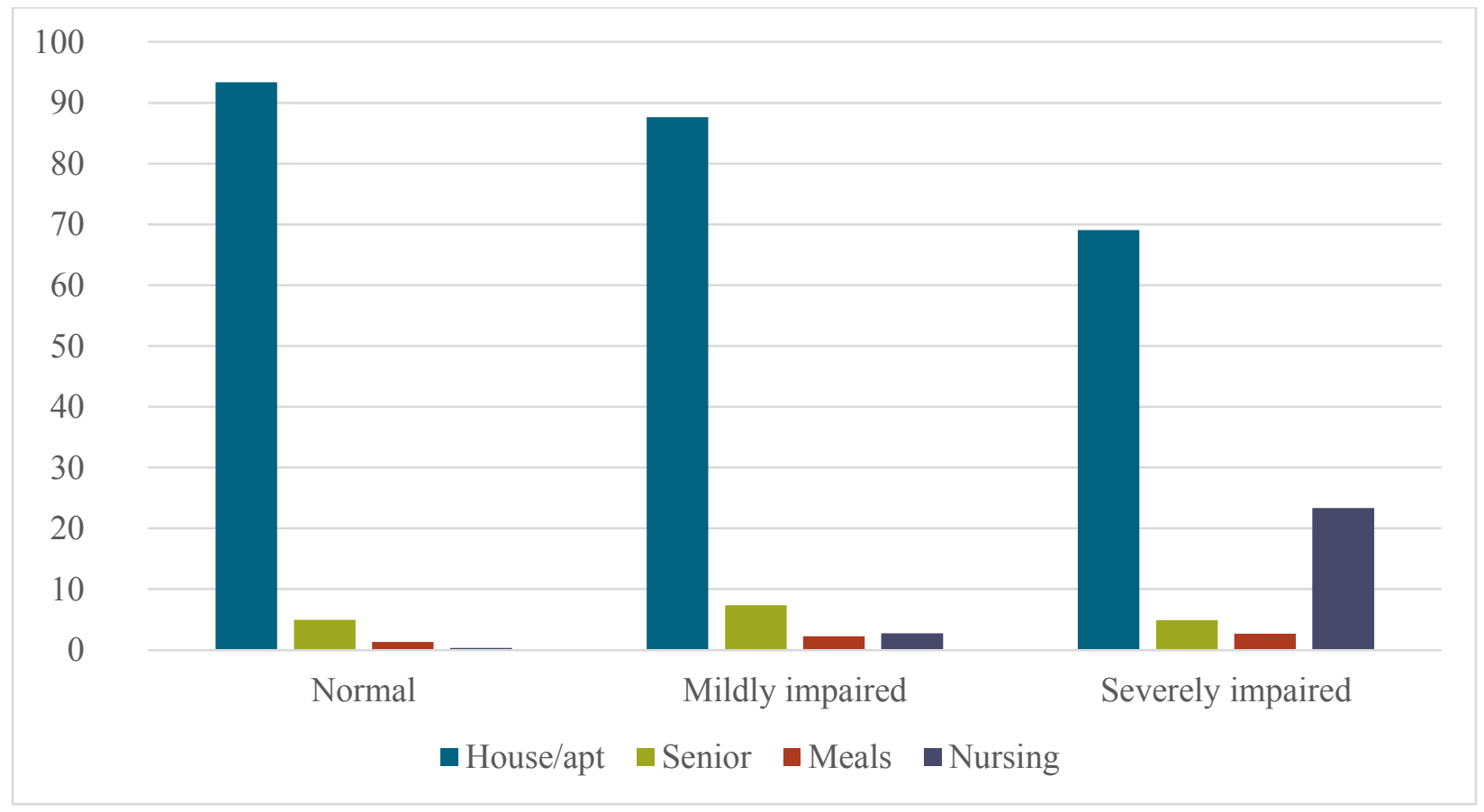

Source: HRS2016 early release, persons 65 and older, authors' sampling weights 
Figure 4 shows the availability of a spouse or partner. Only about 20 percent of severely impaired persons have a cognitively intact spouse or partner. About two-thirds have no surviving spouse, with the remainder having a spouse who has cognitive impairment. Again the patterns primarily reflect the older ages of the severely impaired.

Figure 4: Availability of spouse or partner, by cognitive status

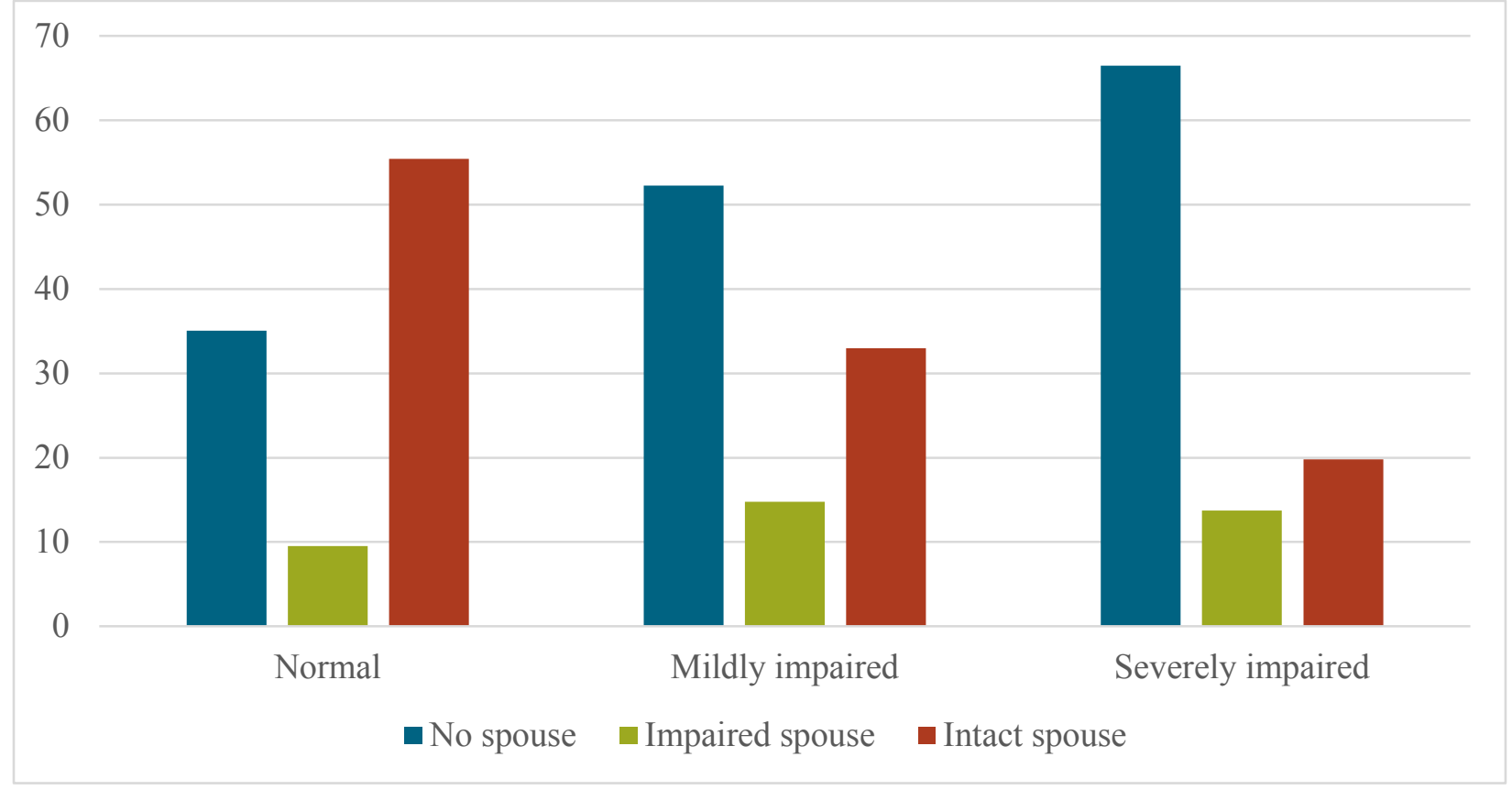

Source: HRS2016 early release, persons 65 and older, authors' sampling weights 
Figure 5: Location of nearest child, by cognitive status

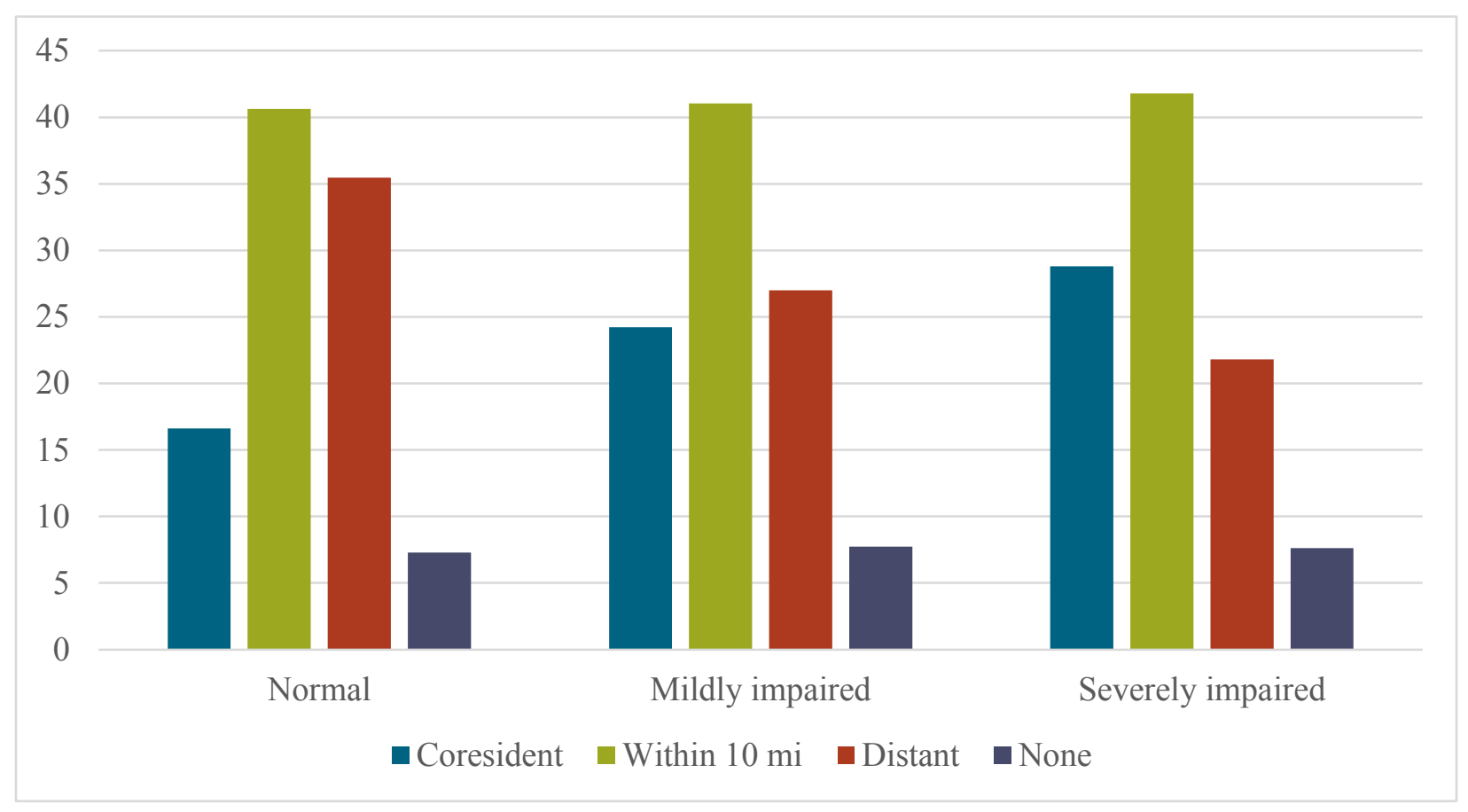

Source: HRS2016 early release, persons 65 and older, authors' sampling weight

Figure 5 illustrates the availability of children. The presence of a coresident child increases with cognitive impairment to nearly 30 percent of the most severely impaired. At all levels of cognitive function, the most common situation is to have a child living nearby, and a majority have a child nearby or living with them. About 20 percent of the severely impaired have no nearby child, and around 7 percent have no surviving children. 
Figure 6: Proximity of Any Potential Assistance, by Cognitive Status (HRS 2016)

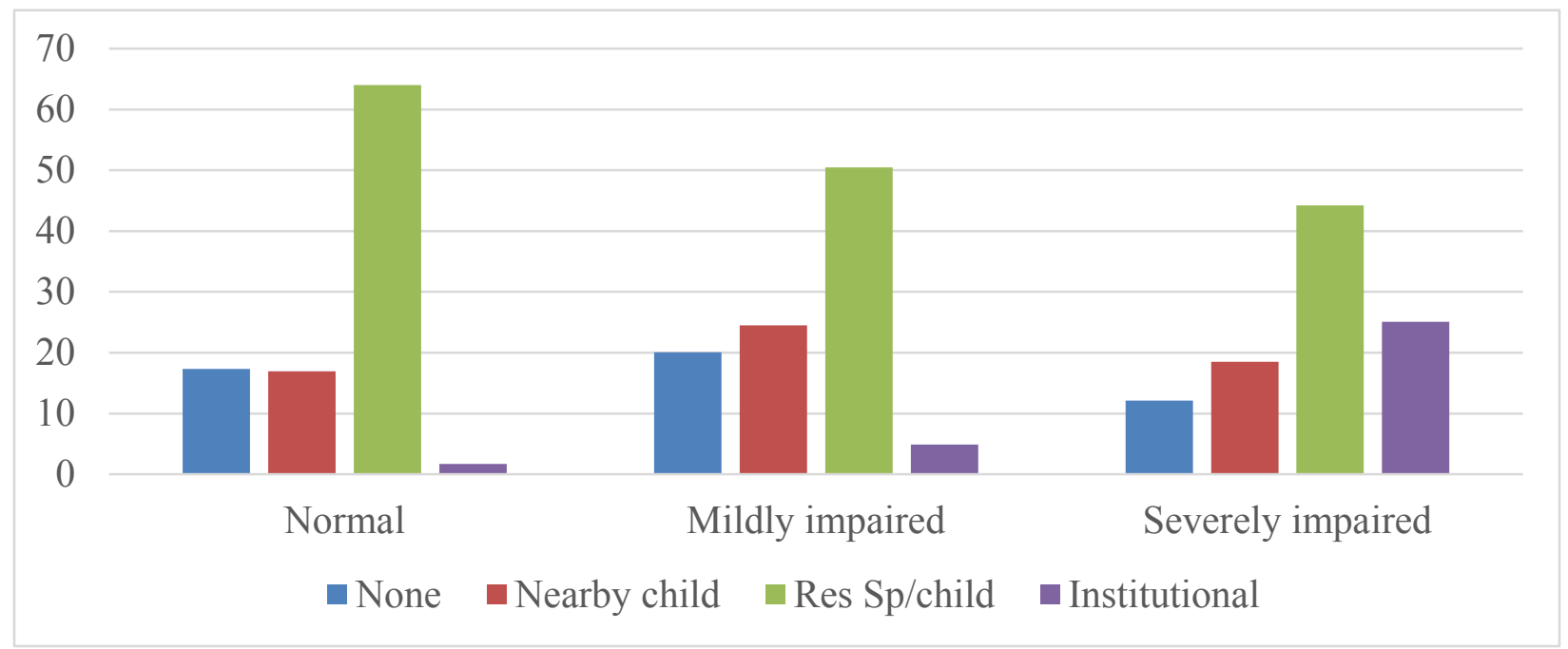

Source: HRS2016 early release, persons 65 and older, authors' sampling weights

Finally, we combine these three sources of potential assistance in Figure 6. Because cognitive impairment is most prevalent among the oldest part of the population, the patterns of potential support by cognitive status follow patterns by age (and gender). Thus, although coresident children become more common with advancing impairment, the availability of a cognitively intact spouse declines even faster. Only about a quarter of the severely impaired reside in institutional settings (nursing homes or assisted living facilities providing meals). Nearly half live in the community with a coresident spouse or child. About 20 percent have a child living nearby, and 12 percent live in the community with no nearby source of family support.

Cognitive impairment is also a gender issue because women are more likely to live to older ages where impairment becomes common. Figure 7 shows the number of men and women with severe cognitive impairment, by proximity to care. Women outnumber men in all categories. Relatively speaking, women with severe impairment are less likely than men to have no locally available support and more likely to live in institutions. Similar to Belbase, Sanzenbacher, and 
King (2018), we find a high prevalence of available family support for the cognitively impaired. We cannot assume, however, that it is always effective support.

Figure 7: Number of men and women with severe cognitive impairment, by proximity to care, in thousands

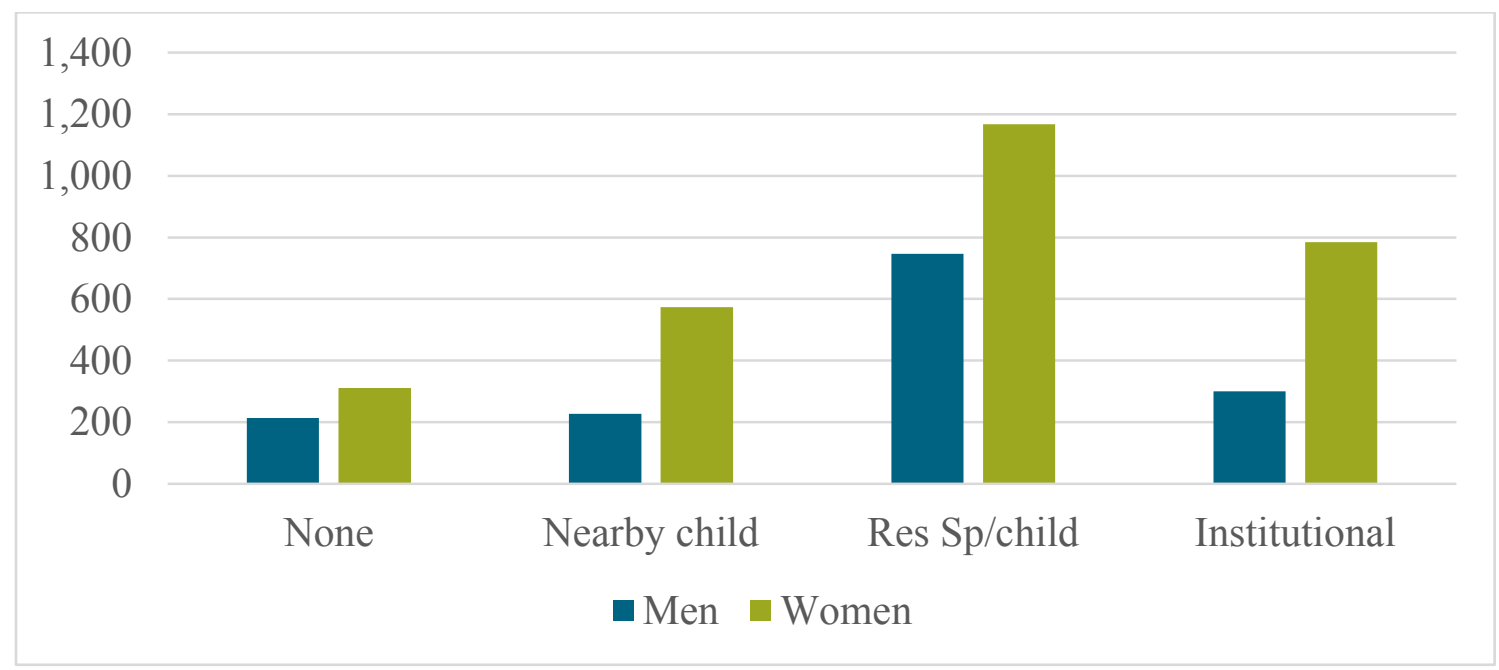

Source: HRS2016 early release, persons 65 and older, authors' sampling weights

\section{Medicare records}

Medicare records are not equivalent to electronic health records (EHR). EHR typically include the results of diagnostic tests and readings from medical charts about diagnoses made by physicians. They can provide a relatively complete description of a patient's health. Medicare records are claims for reimbursement by health care providers. Diagnostic codes are required on these claims, but there is no requirement that each claim report all the conditions a person might have or even all the conditions relevant to that particular incident of care. A further major limitation of Medicare records for diagnostic information is that diagnosis codes are only required on Part A and B claims. Part C Medicare Advantage plans (HMOs) are not required to file encounter-level data with diagnosis codes. Researchers interested in diagnoses commonly limit their analyses to beneficiaries in the fee-for-service (FFS) or traditional Medicare system. However, because beneficiaries can change plans annually, the number of beneficiaries with 
significant time in Medicare Advantage plans is substantially higher than the fraction enrolled in any single year.

Table 1 below shows the distribution of time spent in fee-for-service (FFS) Medicare over the period 2011-15 for HRS Medicare-linked persons 70 or older interviewed in the 2016 wave. Barely half the sample had complete FFS coverage. We use 80 percent of time in FFS as the criterion for being in the FFS sample.

Table 1: Distribution of time spent in traditional Medicare, 2011-15

\begin{tabular}{|cc|}
\hline $\begin{array}{c}\text { Percent of } \text { months in } \\
\text { FFS }\end{array}$ & Percent of sample \\
\hline $0 \%$ & $31 \%$ \\
\hline $1-20 \%$ & $5 \%$ \\
\hline $21-79 \%$ & $9 \%$ \\
\hline $80-99 \%$ & $4 \%$ \\
\hline $100 \%$ & $51 \%$ \\
\hline
\end{tabular}

Figure 1 above showed that Medicare linkage rates in HRS rise with age and are generally high above age 70 . Rates are about 5 percent lower for blacks, and generally unrelated to health and cognitive status. We construct weights adjusting for these factors in nonlinkage so that the sample of persons with Medicare linkage over age 70 represents the same population as all of HRS over age 70. We begin with some analyses limited to the FFS population. That selection is a more stringent one (see Figure 8 below) and requires construction of another set of weights for that subset of the Medicare-linked HRS sample. 
Figure 8: Percent of HRS Medicare-lilnked persons in fee-for-service coverage, by age

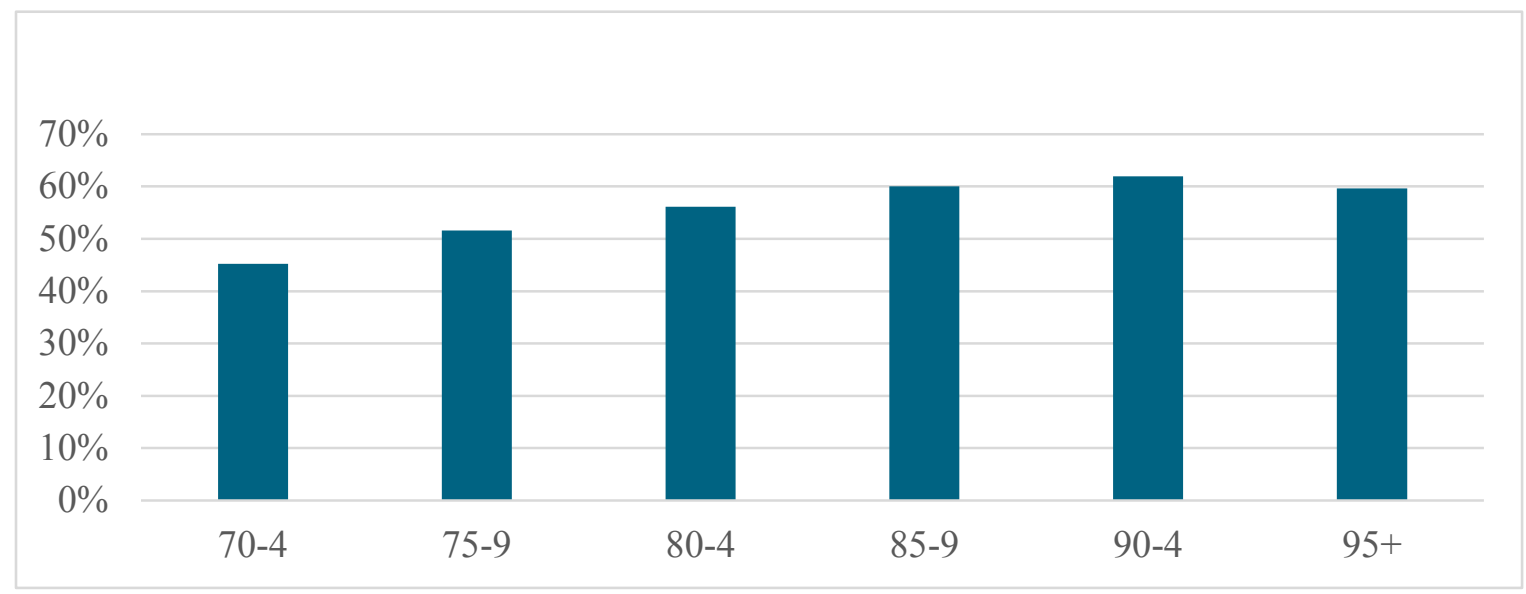

The Chronic Condition Warehouse (CCW) provides algorithms to infer diagnoses of 27 major chronic conditions from the diagnostic codes in Medicare Part A and B claims. We use the $\mathrm{CCW}$ algorithms for Alzheimer's disease and for a broader category of all dementias based on Part A and B claims. The diagnostic codes are shown in Table 2 below. 
Table 2: Diagnostic codes used in the Chronic Condition Warehouse algorithms for Alzheimer's disease and other dementias

\begin{tabular}{|c|c|c|}
\hline \multicolumn{3}{|c|}{ Alzheimer's Disease } \\
\hline ICD-9 code & ICD-10 code & Description \\
\hline 331.0 & G30 & Alzheimer's disease \\
\hline \multicolumn{3}{|c|}{ Related Disorders or Senile Dementia } \\
\hline ICD-9 code & ICD-10 code & Description \\
\hline 331.1 & G31.0 & Frontotemporal dementia (including Pick's disease) \\
\hline 331.2 & G31.1 & Senile degeneration of brain \\
\hline 331.7 & G13.8/G31.2/G94 & Cerebral degeneration \\
\hline 290.0 & F03.9 & Senile dementia, uncomplicated \\
\hline 290.1 & F03.9/F05 & Presenile dementia \\
\hline 290.2 & F03.9/F05 & $\begin{array}{l}\text { Senile dementia with delusional or depressive } \\
\text { feature }\end{array}$ \\
\hline 290.3 & F03.9/F05 & Senile dementia with delirium \\
\hline 290.4 & F01.5 & Vascular dementia \\
\hline 294.0 & F04 & Amnestic disorder in conditions classified elsewhere \\
\hline 294.1 & F02.8 & Dementia in conditions classified elsewhere \\
\hline 294.2 & F03.9 & Dementia, unspecified \\
\hline 294.8 & F06.1/F06.8 & Other persistent mental disorders \\
\hline 797 & R41.81/R54 & Senility without mention of psychosis \\
\hline
\end{tabular}

At first blush, CMS records from Parts A and B appear to do a good job of capturing cognitive impairment in the half of the beneficiary population with mainly FFS coverage. Figure 9 shows the rates of dementia identified in CMS records compared with that based on HRS cognitive measures for the same HRS participants. CMS rates are slightly higher than HRS at all ages except the $95+$. 
Figure 9: Percent with dementia, by age, CMS FFS compared with HRS

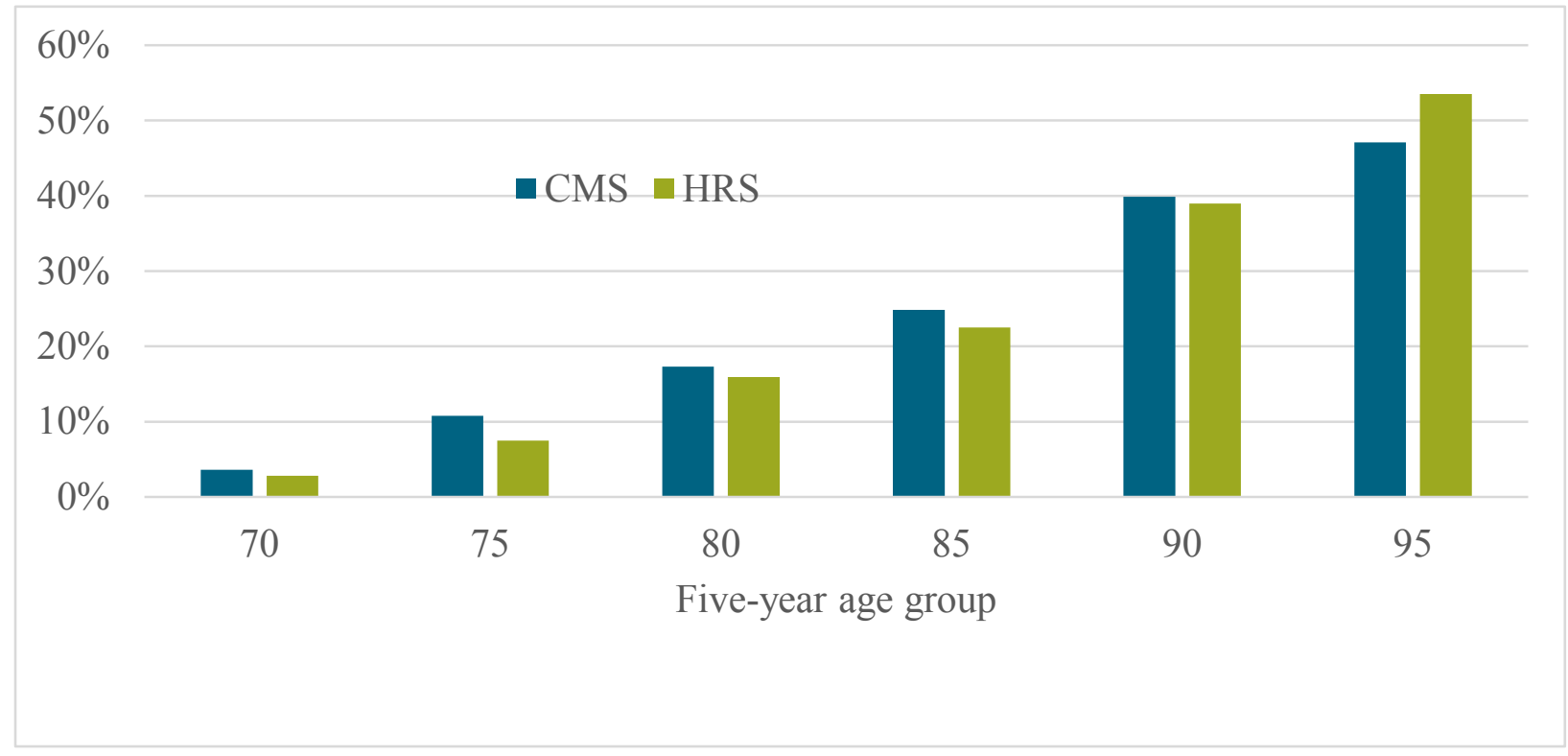

Source: N=3,599 HRS 2016 respondents aged 70 and older with linked CMS records and at least 80 percent of covered months in fee-for-service Medicare in 2011-15, authors' weights

This correspondence in rates by age masks a substantial amount of disagreement at the individual level. Table 3 below shows how the CMS diagnosis compares to the HRS assessment for the same individuals. The sources agree on nearly 80 percent as not having dementia, and another 8.7 percent as being severely impaired. However, they disagree on the remaining 12 percent. If we take the HRS assessment as closer to the true level of functioning, then a CMS indicator of dementia misses 37 percent of the true cases (5.2/13.9), and among those with a CMS indicator of dementia, 44 percent (6.7/15.4) do not have severe impairment. That is a high rate of misclassification even in the half of the population with the best available Medicare data. 
Table 3: Individual comparison of CMS FFS diagnosis with HRS assessment

\begin{tabular}{|llll|}
\hline & HRS & & \\
\hline CMS & No dementia & Dementia & All \\
\hline No dementia & 79.5 & 5.2 & 84.6 \\
\hline Dementia & 6.7 & 8.7 & 15.4 \\
\hline \hline All & 86.1 & 13.9 & 100.0 \\
\hline
\end{tabular}

Note: $\mathrm{N}=3,599$ HRS 2016 respondents aged 70 and older with linked CMS records and at least 85 percent of covered months in fee-for-service Medicare in 2011-15, authors' weights

Focusing on the fee-for-service population clarifies the relationship between CMS diagnoses and direct assessments of function, but it would not make for a viable policy to systematically include or exclude program participants based on their choice of provider for Medicare services. Here we consider a strategy to include all Medicare beneficiaries. Just as the fraction with any time in Medicare Advantage (MA) plans over multiple years is greater than the fraction in a single year, the fraction with any time in FFS Medicare is greater than the fraction in any one year. So there is some Part A and B diagnostic reporting for most beneficiaries. We can then augment this by using Part D prescription drug records. Part D records are especially useful in the MA group because most such plans offer Part D benefits. Conversely, employerprovided prescription drug plans may not be required to report Part D data. In the HRS Medicare-linked sample, the Part D participation rate is 84 percent in the MA group and 66 percent in the FFS group. Four drugs prescribed uniquely for dementia are used to infer the diagnosis: Donepezil (Aricept), galantamine (Razadyne), rivastigmine (Exelon), or memantine (Namenda).

In Table 4 we show the rates of diagnosis by type of coverage and type of claim providing the diagnosis, and compare this to the rate of dementia observed for the same people in HRS. The HRS diagnostic information shows that the coverage types differ substantially in their health. The relatively rare group of Medicare Advantage enrollees with no Part D records are younger and cognitively much healthier. Conversely, fee-for-service enrollees with Part D coverage have 
the highest rates of dementia. Overall, the rate of dementia identified in Medicare records is nearly identical to that in HRS (11.7 percent versus 11.6 ). This also tracks reasonably well by coverage type, but fee-for-service beneficiaries have higher diagnosis rates in Medicare than in HRS, and Medicare Advantage somewhat lower. Part D prescription drug records are highly specific for dementia, but because half or more of people with dementia don't take drugs for it, it fails to identify a significant number. Part D data add very little to diagnoses in the fee-forservice population, but do add in the Medicare Advantage group.

Table 4: Diagnoses of Alzheimer's Disease or Other Dementias in Medicare Parts A, B, and D Compared with HRS, by Types of Medicare Coverage

\begin{tabular}{|llllll|}
\hline Coverage Type & \multicolumn{5}{l|}{ Diagnosis rates } \\
\hline & \%of ben & Parts A/B & Part D & total & HRS \\
\hline MA no PartD & $5.4 \%$ & $2.2 \%$ & $0.0 \%$ & $2.2 \%$ & $2.6 \%$ \\
\hline MA+PartD & $41.2 \%$ & $7.0 \%$ & $4.7 \%$ & $9.3 \%$ & $11.2 \%$ \\
\hline FFS only & $18.4 \%$ & $12.3 \%$ & $0.0 \%$ & $12.3 \%$ & $9.1 \%$ \\
\hline FFS+PartD & $34.8 \%$ & $15.2 \%$ & $6.4 \%$ & $15.9 \%$ & $14.8 \%$ \\
\hline & & & & & \\
\hline All & $100.0 \%$ & $10.6 \%$ & $4.2 \%$ & $11.7 \%$ & $11.6 \%$ \\
\hline
\end{tabular}

Note: N=6,676 HRS 2016 respondents aged 70 and older with linked CMS records, authors' weights.

Diagnosis rates from all available Medicare records are similar in overall level, and by age, to rates based on cognitive assessments in HRS. At the individual level, however, the match remains imperfect. Table 5 shows the comparison. The great majority of seniors are not impaired, and Medicare records and HRS assessments agree on 83 percent as unimpaired and agree on another 6.6 percent as impaired. Roughly equal numbers of approximately 5 percent of the population are rated as impaired by only one source. 
Table 5: Individual comparison of CMS all-source diagnosis with HRS assessment

\begin{tabular}{|llll|}
\hline & & HRS & \\
\hline CMS & No dementia & Dementia & All \\
\hline No dementia & 83.3 & 5.0 & 88.3 \\
\hline Dementia & 5.2 & 6.6 & 11.8 \\
\hline \hline All & 88.4 & 11.6 & 100.0 \\
\hline
\end{tabular}

Note: $\mathrm{N}=6,676$ HRS 2016 respondents aged 70 and older with linked CMS records, authors' weights.

Adding in the Medicare Advantage population and Part D data expands coverage to the entire population. It increases the estimate of missing cases from 37 percent to 44 percent and lowers the rate of false positives in CMS from 44 percent to 43 percent. It is important to determine whether HRS is in fact closer to the truth. In a previous analysis of discordance between CMS and HRS on diabetes diagnosis we were able to use blood tests to demonstrate that the cases diagnosed by CMS but not HRS had relatively low levels of hemoglobin A1c, a marker of sustained high blood sugar (Sakshaug, Weir, and Nicholas 2014). Relatively few cases had an HRS diagnosis and not a CMS diagnosis but they had higher levels of Alc. Here we can take advantage of the Healthy Cognitive Aging Project (HCAP), an in-depth study of cognitive function undertaken with a random sample of HRS participants following the 2016 wave of interviews. The HCAP administered an hour of cognitive testing to the respondent and collected extensive data from an informant. The HCAP data are not yet ready for release but we provide here some evidence from well-known measures. Table 4 shows scores on the Mini-Mental State Examination (MMSE), a well-known screening test for dementia, and the Jorm IQCODE, a wellknown informant screener for dementia. The cases with agreement are clearly far apartpersons with dementia score much lower on MMSE and receive higher scores on the IQCODE, indicating more cognitive problems. The cases of disagreement fall between these agreed cases, but the cases identified by CMS and not by HRS are substantially closer to the normal group and the cases identified by HRS and not by CMS are closer to the group with agreed dementia. 
Table 6: Characteristics of people by diagnosis type: detailed cognitive measures from HCAP

\begin{tabular}{|lll|}
\hline Impairment & MMSE & Jorm IQCODE \\
\hline None & 27.4 & 3.18 \\
\hline CMS only & 25.3 & 3.49 \\
\hline HRS only & 20.6 & 3.76 \\
\hline Both & 17.2 & 4.40 \\
\hline
\end{tabular}

Note: $\mathrm{N}=2,360$ HRS-HCAP 2016 respondents 70 and older with Medicare linkage. Unreleased HCAP data, authors' weights

\section{Need for assistance with financial management}

We have seen substantial misclassification of severity of cognitive impairment from using CMS records in place of direct assessment. A further difficulty arises from the fact that not all impaired persons perceive a need for assistance with financial management, while some less impaired persons do, and family members often disagree with the individual on this need. Table 7 shows how respondents and a family informant compare in their assessments of difficulty managing finances. Respondents in HRS (or their proxies) are asked: “ do you have any difficulty with managing your money — such as paying your bills and keeping track of expenses?" Informants in HCAP were asked several questions about difficulty managing finances which we have collapsed into a four-point scale. Only about 9 percent of respondents felt they had such difficulty, and the share of informants who thought there was some or severe levels of difficulty was about the same. But they are not necessarily the same people. Only twothirds of people rated by informants as having severe difficulty said they had any difficulty (4.2/6.3). One-quarter of respondents who reported some difficulty were rated by their informants as having no difficulty (2.3/9.1). We noted before that most older persons with cognitive impairment had family support available. This level of internal disagreement about need for assistance with financial management indicates how difficult it may be to coordinate family support and government assistance with cognitive impairment. 
Table 7: Perceived difficulty with financial management: respondent self-report (HRS 2016) compared with family informant (HCAP 2016)

\begin{tabular}{|llll|}
\hline & Respondent report & & \\
\hline $\begin{array}{l}\text { Informant } \\
\text { report }\end{array}$ & No diff & Some diff & All \\
\hline No diff & 77.3 & 2.3 & 79.6 \\
\hline 1 mild & 5.1 & 0.7 & 5.8 \\
\hline Some diff & 6.3 & 2.0 & 8.2 \\
\hline Severe diff & 2.2 & 4.2 & 6.3 \\
\hline \hline Total & 90.9 & 9.1 & 100.0 \\
\hline
\end{tabular}

Note: N=3,178 HRS-HCAP 2016 respondents 65 and older. Unreleased HCAP data, authors' weights

We can also relate these reports of difficulty managing finances to diagnoses of cognitive impairment as in Table 8. Three percent of respondents and 9 percent of informants of unimpaired persons in HRS or CMS report some difficulty. Twenty percent of that group failed to get any items correct on a simple test of basic numeracy such as would be needed to understand a sale offering. At the other end, three-quarters of respondents and nearly 90 percent of informants reported difficulty managing money among the group with agreed diagnosis of dementia. The group diagnosed with dementia in CMS but not HRS again looks more impaired than the group with agreed no impairment, but much less impaired than the group with agreed impairment. The HRS-only group is closer to the impaired. Interestingly, they do even worse on the numeracy test than the agreed impaired group, but only about half say they have difficulty with financial management. 
Table 8: Characteristics of people by diagnosis type: reported difficulty with financial management and numeric ability

\begin{tabular}{|llll|}
\hline & & \multicolumn{2}{l|}{ Difficulty with money reported by } \\
\hline Impairment & $\begin{array}{l}\text { Zero correct on } \\
\text { numeracy }\end{array}$ & Respondent & Informant \\
\hline None & $20.5 \%$ & $3.3 \%$ & $8.9 \%$ \\
\hline CMS only & $31.2 \%$ & $13.9 \%$ & $37.5 \%$ \\
\hline HRS only & $67.1 \%$ & $49.6 \%$ & $54.5 \%$ \\
\hline Both & $61.7 \%$ & $76.6 \%$ & $89.2 \%$ \\
\hline
\end{tabular}

Note: $N=6,676$ HRS 2016 Early Release respondents 70 and older with Medicare linkage. N=2,360 HRSHCAP 2016 informants. Unreleased HCAP data, authors' weights

We incorporate HRS data on reported difficulty with financial management to arrive at a comprehensive picture of how well Medicare records address this need. Approximately 2 million people 70 and older live in nursing homes or other institutional settings that could be identified by address. Table 9 summarizes how well Medicare records do at identifying seniors with cognitive impairment or needing assistance with financial management living in the community. Of the approximately 3.8 million community-dwelling seniors 70 and older with a perceived need for assistance or severe cognitive impairment, Medicare records identify 1.5 million. In addition, Medicare records identify 1.2 million people who have no or mild impairment and no perceived need for financial assistance.

Table 9: Medicare Records as Indicators for Need for Assistance with Financial Management in the Population 70 and Older (Estimated Population Totals, in 000s)

\begin{tabular}{|llll|}
\hline \multicolumn{3}{c|}{ CMS diagnosis } \\
\hline Need status & No & Yes & All \\
\hline Need financial assistance & 1,511 & 1,067 & 2,578 \\
\hline Don't need assistance & & & \\
\hline Severely impaired & 757 & 437 & 1,194 \\
\hline Mildly impaired & 5,610 & 634 & 6,244 \\
\hline No impairment & 20,208 & 646 & 20,854 \\
\hline & & & \\
\hline Total & 28,087 & 2,785 & 30,872 \\
\hline
\end{tabular}




\section{Conclusion}

Medicare records are an imperfect guide to cognitive impairment as a medical diagnosis. They are even worse as a guide to who perceives or is perceived by others as needing assistance with financial management. Outside of institutional settings, Medicare records identify fewer than half the people needing assistance with financial management, and point to a substantial number of people who say they do not. 


\section{References}

Belbase, Anek, Geoffrey T. Sanzenbacher \& Sara Ellen King. 2018. Cognitive Impairment and Social Security's Representative Payee Program. Journal of Aging \& Social Policy

Crimmins, E.M., Kim, J.K., Langa, K.M., \& Weir, D.R. 2011. Assessment of cognition using surveys and neuropsychological assessment: the health and retirement study and the aging, demographics, and memory study. The Journals of Gerontology, Series B: Psychological Sciences and Social Sciences, 66B(S1), i162-i171

Hurd, Michael D., Paco Martorell, Adeline Delavande, Kathleen J. Mullen, and Kenneth M. Langa. 2013. "Monetary costs of dementia in the United States." New England Journal of Medicine 368, no. 14: 1326-1334.

Langa, K. M., Kabeto, M., \& Weir, D. 2009. Report on race and cognitive impairment using HRS in, 2010 Alzheimer's disease facts and figures. Retrieved from http://www.alz.org/documents_custom/report_alzfactsfigures2010.pdf.

Sakshaug Joseph W, David R Weir, and Lauren H Nicholas. 2014. "Identifying diabetics in Medicare claims and survey data: implications for health services research," BMC Health Services Research, 14:150, pp.1-6 